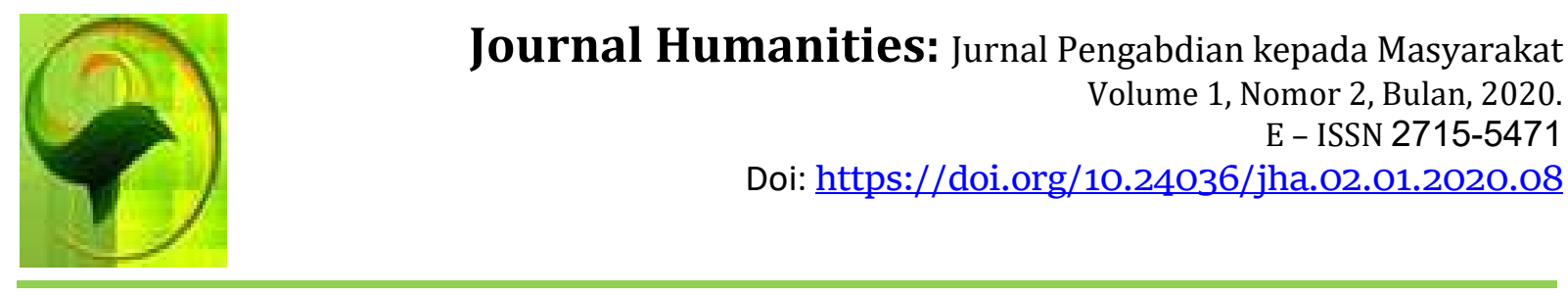

\title{
Build Awareness Of The Hamlet Of Both Rajumas About The Cleanliness Of The Health \& The Environment Community
}

\author{
${ }^{1}$ Suryansah, ${ }^{2}$ Hariadi, ${ }^{3}$ Rina Nopiana \\ 1,2,3 Fakultas Ilmu Pendidikan, Universitas Hamzanwadi, Indonesia \\ Email: suryansah@hamzanwadi.ac.id ${ }^{1}$,hariadi121113@gmail.com ${ }^{2}$, nopianar@gmail.com $^{3}$
}

\begin{abstract}
This community service has been carried out from July to August 2020 in Dusun Rajumas, Mantang Village, Batukliang District. This service aims to build, grow and increase community awareness, especially the Rajumas hamlet, to cleanliness and environmental health because the environment or the Rajumas hamlet will become village tourism and hygiene and health tourism. This service is carried out in the form of observation, action and counseling on the importance of cleanliness and environmental health itself, as well as field action in the form of community service involving youth or young Rajumas who form an organization called Garuda Emas youth to participate and play an active role in improving hygiene and health. environment. After the service was completed, the level of concern of some people to environmental hygiene and health began to increase. This can be seen from the increase in their active role and enthusiasm in participating in field action activities in improving environmental hygiene and health.
\end{abstract}

Keywords: Building, Hygiene, Health, Environment

\begin{abstract}
Abstrak
Pengabdian masyarakat ini telah dilaksanakan pada bulan Juli hingga Agustus 2020 di Dusun Rajumas Desa Mantang Kecamatan Batukliang. Pengabdian ini bertujuan untuk membangun, menumbuhkan dan meningkatkan kepedulian masyarakat khususnya dusun rajumas terhadap kebersihan dan kesehatan lingkungan dikarnakan lingkungan atau dusun rajumas akan menjadi wisata desa dan wisata kebersihan dan kesehatan. Pengabdian ini dilakukan dalam bentuk observasi, tindakan dan penyuluhan tentang pentingnya kebersihan dan kesehatan lingkungan itu sendiri, serta aksi lapangan dalam bentuk kerja bakti yang melibatkan para remaja atau pemuda rajumas yang membentuk organisasi namanya pemuda garuda emas ikut serta dan berperan aktif untuk meningkatkan kebersihan dan kesehatan lingkungan. Setelah pengabdian selesai, tingkat kepedulian sebagian masyarakat terhadap kebersihan dan kesehatan lingkungan mulai meningkat. Hal ini dapat dilihat dari peningkatan peran aktif dan antusiasme mereka dalam mengikuti kegiatan aksi lapangan dalam meningkatkan kebersihan dan kesehatan lingkungan.
\end{abstract}

Keywords: Membangun, Kebersihan, Kesehatan, Lingkungan

\section{ANALISIS SITUASI}

Banyak aktivitas masyarakat yang berdampak buruk terhadap kualitas lingkungan diri sendiri, misalnya pengelolaan sampah dan limbah yang kurang baik dilingkungan sekitarnya, meningkatnya penggunaan bahan-bahan yang tidak mampu didegradasi oleh alam contohnya pelastik keresek dan sejenisnya, meningkatnya jumlah dan penggunaan kendaraan pribadi dan kendaraan yang tidak layak jalan, dan operasi industri yang berpengelolaan buruk. Perencanaan tata ruang dan wilayah yang tidak mempedulikan kaidah pelestarian lingkungan, kelemahan birokrasi, penegakan hukum dan kelembagaan juga menjadi factor penting yang mempengaruhi kualitas lingkungan itu sendiri. Kepedulian masyarakat disekitarnya yang sangatlah rendah dan mementingkan diri sendiri terhadap kebersihan dan kesehatan lingkungan semakin terpuruk atau memperparah kondisi lingkungan tersebut. Bukan sebagian orang melainkan banyak masyarakat yang membuang sampah disungai atau selokan yang dapat menyebabkan meluapnya air sungai, selokan atau banjir yang tidak terduga datangnya kapan. Bahkan banyak berdiri bangunan permanin dan bangunan ruko-ruko yang tidak 
${ }^{1}$ Suryansah, ${ }^{2}$ Hariadi, ${ }^{3}$ Rina Nopiana

memikirkan saluran air pembuangan sehingga air tidak mengalir normal atau sistem drainase yang tidak berjalan karena banyaknya peyumbatan. Rendahnya kualitas lingkungan tersebut akan berdampak dan merembet terhadap kesehatan masyarakat sekitarnya. Lingkungan yang tidak terawat, kumuh dan kotor akan menjadi tempat berkembangnya berbagai macam mikroorganisme penyebab penyakit dan organisme vaktor pembawa penyakit. Akibatnya masyarakat menjadi rentan terhadap berbagai macam penyakit. Kondisi ini jelas akan menghambat pembangunan yang sedang dijalankan. Permasalahan yang ada pada mitra saat ini antara lain adalah:

a. Kesadaran masyarakat yang masih rendah terhadap permasalahan kebersihan dan kesehatan lingkungan

b. Pengetahuan masyarakat yang masih rendah dalam hal pengelolaan lingkungan hidup.

c. Partisipasi masyarakat yang masih rendah dalam hal kebersihan dan kesehatan lingkungan.

d. Belum adanya program percontohan pengelolaan lingkungan hidup hingga tingkat Rukun Tetangga atau rukun Warga.

e. Kondisi kebersihan dan kesehatan lingkungan yang masih memprihatinkan pada beberapa lokasi.

f. Pengelolaan sampah organic dan non organic

g. Bang sampah yang belum diterapkan maupun belum diberlakukan seperti kota-kota besar lainnya.

h. Tidak ada tempat pembuangan sampah sementara dan para pengangkut sampah yang teratur mengambil sampah maka dari itu sampah menjadi numpuk dan bauk menyengat

i. Membuang sampah di sungai kali.

\section{SOLUSI DAN TARGET}

Jika pemerintah melaksanakan tugas dengan baik dalam menciptakan kebersihan dan kesehatan lingkungan, dan kemudian masyarakat ikut serta memelihara kebersihan lingkungannya, maka dapat kita lihat alangkah indahnya kondisi lingkungan tempat kita melaksanakan aktivitas sehari-hari, tempat tinggal dan kekeluargaan. Oleh karena itu, kita harus memulai dari hal yang sangat terkecil dan harus mulai dari sendiri dan lingkungan terdekat dalam upaya menjaga kebersihan dan kesehatan lingkungan. Maka dari itu para pemuda pemudi dusun rajumas yang menamakannya garuda emas berinisiatif dan berkerjasama dalam menjalankan program pemerintah, masyarakat maupun desa setempat. Kecamatan batukliang desa mantang dusun rajumas merupakan salah satu dusun di desan mantang yang menggagas dan membangun dusun rajumas ini menjadi bersih, sehat dan akan mengajukan menjadi desa wisata yang terunggul dari dusun-dusun sekitarnya.

Dimana dusun rajumas yang dilewati oleh aliran sungai Kalin yaitu pasar mantang. Kali merupakan sebuah sungai kecil tetapi menjadi saluran air hujan sehingga jika hujan turun relatif lebat, Kali tidak mampu menampung dan selalu terjadi luapan air hujan kedalam permukiman maupun kelingkungan sekitarnya. Keadaan ini menyebabkan terjadinya banjir yang meluap di jalan-jalan di wilayah mantang dusun rajumas. Banjir yang terjadi selalu membawa sampah dan meninggalkannya di jalan-jalan yang dilalui.

Warga rajumas secara umum tingkat ekonomi dan tingkat pendidikannya sangat beragam. Warga yang bertempat tinggal di sepanjang jalur Kali dan berdampingan dengan pasar tradisional mantang umumnya adalah warga yang tinggkat ekonomi dan pendidikannya relatif rendah. Kesadaran warga tersebut terhadap kebersihan dan kesehatan lingkungan juga masih rendah. Hal ini dapat dilihat dari pengelolaan lingkungan yang sangat minim dari warga setempat dan para pedagang maupun tukang kebersihan pasar membuang sampah maupun membuang kotoran pasar tradisionalnya ke sungai kali sehingga kondisi lingkungan menjadi tidak terawat apalagi pada saat musim hujan. Sampah berserakan di mana-mana, rumput liar tumbuh subur dan saluran air selokan yang tidak lancar.

\section{METODE PELAKSANAAN}

Metode yang digunakan dalam pengabdian kepada masyarakat ini adalah metode observasi, dokumentasi, Penyuluhan, Diskusi dan Aksi Lapangan. Selama kegiatan, materi penyuluhan disajikan dengan alokasi waktu $20 \%$, sedangkan $80 \%$ untuk diskusi sehingga para peserta lebih aktif dan kegiatan secara keseluruhan menjadi lebih bersemangat dan lebih efektif. 


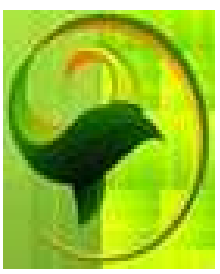

Journal Humanities: Jurnal Pengabdian kepada Masyarakat

Volume 1, Nomor 2, Bulan, 2020.

E - ISSN 2715-5471

Doi: https://doi.org/10.24036/jha.02.01.2020.08

\section{PELAKSANAAN KEGIATAN}

Adapun tahap-tahap pelaksanaan pengabdian adalah sebagai berikut.

1. Perencanaan

Tim Pengabdian berkoordinasi dengan Kepala Kelurahan, Ketua RW, Ketua RT dan para sesepuh dilingkungan dusun rajumas untuk menyusun rencana pelaksanaan kegiatan yang meliputi Penyuluhan dan diskusi, setelah itu aksi lapangan Koordinasi dilakukan berkaitan dengan penentuan jadwal pertemuan, tempat dan agenda pertemuan.

2. Pelaksanaan

Penyampaian materi penyuluhan dilakukan oleh Tim dan bekerja sama dengan perangkat

RT dan RW dalam menyediakan sarana dan prasarana. Kegiatan penyuluhan ini dibagi menjadi dua sesi, yaitu sesi penyampaian materi dan sesi diskusi dengan perbandingan waktu $20 \%$ penyampaian materi dan $70 \%$ diskusi. Adapun materi penyuluhan meliputi:

Table 1. Materi penyuluhan kebersihan dan kesehatan lingkungan

\begin{tabular}{|c|c|c|c|c|}
\hline No & Materi & Metode & Pelaksanaan & Alokasi Waktu \\
\hline 1 & $\begin{array}{l}\text { Arti penting kesehatan dan } \\
\text { kebersihan lingkungan }\end{array}$ & $\begin{array}{l}\text { Ceramah } \\
\text { Diskusi }\end{array}$ & Rina Nopiana. M.Pd & $\begin{array}{c}\text { Ceramah } 20 \% \\
\text { Diskusi } 80 \%\end{array}$ \\
\hline 2 & $\begin{array}{l}\text { Tujuan dan manfaat kesehatan } \\
\text { dan kebersihan lingkungan }\end{array}$ & $\begin{array}{l}\text { Ceramah } \\
\text { Diskusi }\end{array}$ & Suryansah. M.Pd & $\begin{array}{c}\text { Ceramah } 20 \% \\
\text { Diskusi } 80 \%\end{array}$ \\
\hline 3 & $\begin{array}{l}\text { Teknik dan hubungan } \\
\text { menjaga kebersihan dan } \\
\text { kesehatan lingkungan }\end{array}$ & $\begin{array}{l}\text { Ceramah } \\
\text { Diskusi }\end{array}$ & Hariadi. M.Pd & $\begin{array}{c}\text { Ceramah 20\% } \\
\text { Diskusi } 80 \%\end{array}$ \\
\hline 4 & $\begin{array}{l}\text { Peran masyarakat agar } \\
\text { menjadi Desa wisata }\end{array}$ & $\begin{array}{l}\text { Ceramah } \\
\text { Diskusi }\end{array}$ & Irwan Rahadi. M.Sc & $\begin{array}{c}\text { Ceramah } 20 \% \\
\text { Diskusi } 80 \%\end{array}$ \\
\hline 5 & Aksi lapangan & $\begin{array}{l}\text { Gotong } \\
\text { Royong }\end{array}$ & Tim, Polisi, TNI & $\begin{array}{l}\text { Setiap sore hari \& } \\
\text { Minggu Pagi hari } \\
\text { s.d. sore hari } \\
\end{array}$ \\
\hline
\end{tabular}

Tabel 2. Jadwal kegiatan pelaksanaan penyuluhan kebersihan dan kesehatan lingkungan

\begin{tabular}{|c|c|c|}
\hline No & Materi & Jadwal \\
\hline 1 & Perijinan, Surve lokasi dan Observasi aksi lapangan & $\begin{array}{l}\text { Kamis } 2 \text { Juli } 2020 \\
\text { Pukul: } 08.00-10.00\end{array}$ \\
\hline 2 & $\begin{array}{l}\text { Penyuluhan } 1 \\
>\quad \text { Arti penting kesehatn dan kebersihan lingkungan } \\
\text { (Ceramah, Diskusi Praktik/simulasi) } \\
>\quad \text { Tujuan dan manfaat kesehatan dan kebersihan } \\
\text { lingkungan (Ceramah, Diskusi Praktik/simulasi) }\end{array}$ & $\begin{array}{l}\text { Minggu 12 Juli } 2020 \\
\text { Pukul : 08.30-01.00 }\end{array}$ \\
\hline 3 & $\begin{array}{l}\text { Penyuluhan } 2 \\
\text { Teknik dan hubungan menjaga kebersihan dan } \\
\text { kesehatan lingkungan (Ceramah, Diskusi } \\
\text { Praktik/simulasi) } \\
>\quad \text { Peran masyarakat agar menjadi Desa wisata } \\
\quad \text { (Ceramah, Diskusi Praktik/simulasi) }\end{array}$ & $\begin{array}{l}\text { Minggu 19 Juli } 2020 \\
\text { Pukul: 08.30-01.00 }\end{array}$ \\
\hline 4 & $\begin{array}{l}\text { Aksi lapangan } \\
\text { (Membersihkan Selokan, Sungai kali), (Membersihkan } \\
\text { rumput ilalang), (Memisahkan sampah organic dan non }\end{array}$ & $\begin{array}{l}\text { 1. Minggu 26 Juli } 2020 \\
\text { Pukul: 09.00-04.00 } \\
\text { 2. Minggu 2 Agustus }\end{array}$ \\
\hline
\end{tabular}


${ }^{1}$ Suryansah, ${ }^{2}$ Hariadi, ${ }^{3}$ Rina Nopiana

\begin{tabular}{|l|l|l|}
\hline organic), (pengelolaan sampah), (menanam sayur- & 2020 \\
& sayuran, cabe dan bunga d halaman rumah menggunakan & Pukul: 09.00-04.00 \\
pot maupun media tanam yang lebih besar), (Mengecat & 3. Minggu 9 Agustus \\
Tembok Lingkungan agar indah dan menarik), (menata & 2020 \\
& Pukul: 09.00-04.00 \\
\hline
\end{tabular}

\section{HASIL DAN PEMBAHASAN}

Secara umum dan keseluruhan alhamdulilah kegiatan pengabdian kepada masyarakat berjalan dengan lancar sesuai dengan rencana yang telah dibuat. Penyuluhan dan diskusi telah dilakukan sebanyak dua kali pertemuan dengan 4 tema materi. Sedangkan aksi lapangan telah dilakukan sebanyak tiga kali yaitu (membersihkan selokan, sungai kali), (Membersihkan rumput ilalang), (Memisahkan sampah organic dan non organic), (pengelolaan sampah), (menanam sayur-sayuran, cabe dan bunga $\mathrm{d}$ halaman rumah menggunakan pot maupun media tanam yang lebih besar), (Mengecat Tembok Lingkungan agar indah dan menarik), (menata tempat cuci tangan di setiap depan rumah).
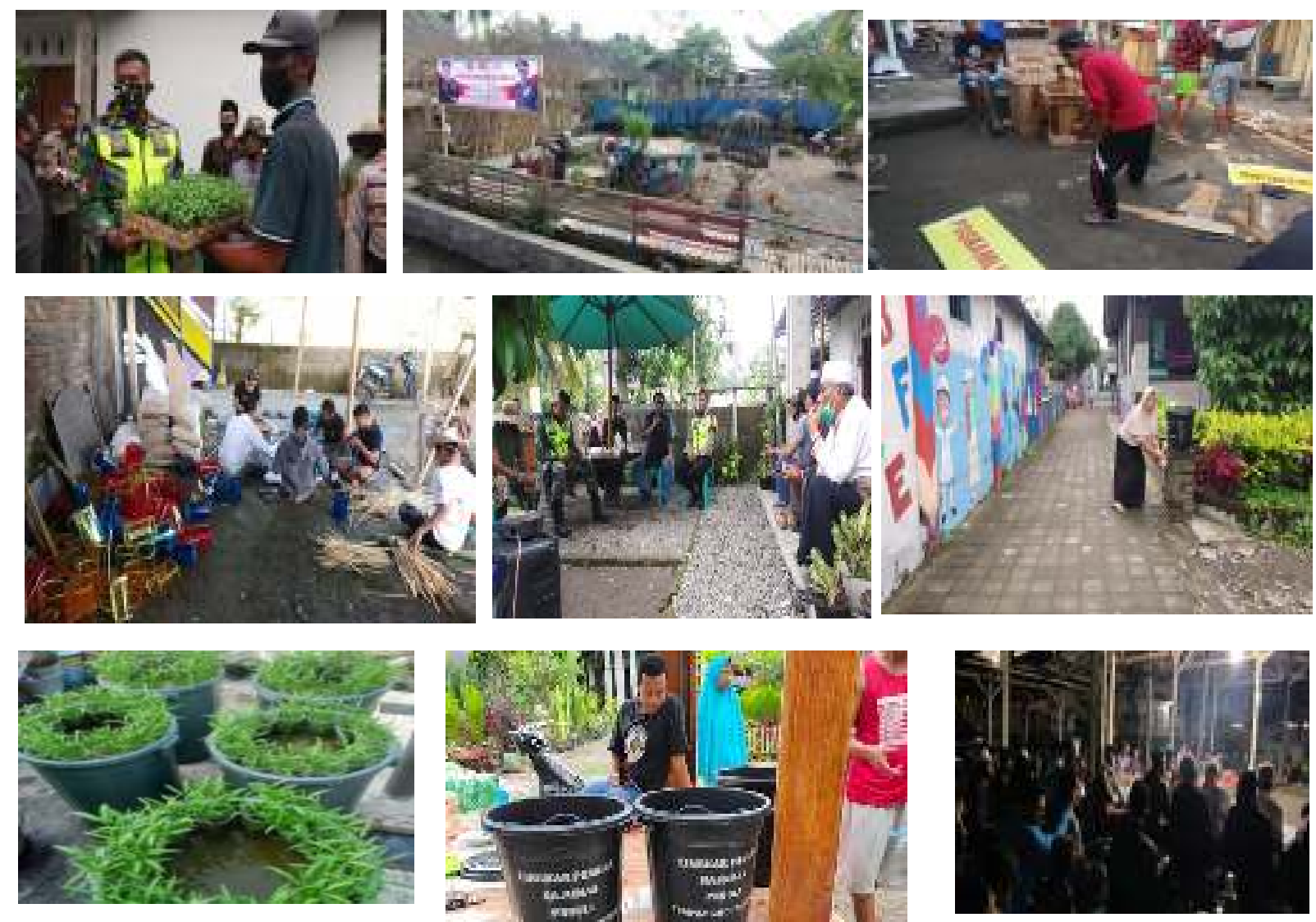

Gamabar 1. Kegiatan pelaksanaan penyuluhan kebersihan dan kesehatan lingkungan dalam membangun wisata dusun rajumas

\section{KESIMPULAN}

Dari kegiatan yang telah dilakukan dapat disimpulkan bahwa pada mulanya kesadaran masyarakat terhadap kebersihan dan kesehatan lingkungan masih rendah. Hal ini menyebabkan rendahnya motivasi dan semangat sebagian masyarakat untuk mengikuti kegiatan pengabdian ini. Namun setelah dilakukan pendekatan banyak warga yang dengan penuh semangat mengikuti kegiatan tersebut sampai selesai. Kegiatan pengabdian ini secara umum dapat meningkatkan pemahaman dan kesadaran masyarakat terhadap kebersihan dan 


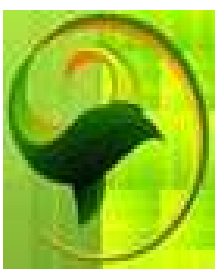

Journal Humanities: Jurnal Pengabdian kepada Masyarakat

Volume 1, Nomor 2, Bulan, 2020.

E - ISSN 2715-5471

Doi: https://doi.org/10.24036/jha.02.01.2020.08

kesehatan lingkungan sehingga pada akhir kegiatan motivasi masyarakat untuk mengelola lingkungan mereka semakin baik.

Hal ini terlihat pada tingginya tingkat partisipasi masyarakat pada kegiatan aksi lapangan. Kegiatan pengabdian masyarakat tentang kebersihan dan kesehatan lingkungan masih sangat diperlukan oleh masyarakat sehingga disarankan kegiatan serupa untuk dilaksanakan kembali pada waktu-waktu mendatang, atau dilakukan pada daerah lainnya.

\section{PENGAKUAN}

Alhamdulilah keberhasilan pengabdian kepada masyarakat ini tentunya tidak terlepas dari berbagai kekurangan dan keterbatasan kami sebagai pasilitator dan semua masyarakat dusun rajumas oleh karna itu kami haturkan terimakasih banyak kepada Kepala Desa Mantang, RT, RW dan para pemuka agama, sesepuh dan para pemuda dusun rajumas

\section{DAFTAR PUSTAKA}

Andriyani, A. A. I. (2017). Pemberdayaan Masyarakat Melalui Pengembangan Desa Wisata dan Implikasinya terhadap Ketahanan Sosial Budaya Wilayah (Studi di Desa Wisata Penglipuran Bali). Jurnal Ketahanan Nasional, 23(1), 1-16.

Andayani, A. A. I., Martono, E., \& Muhamad, M. (2017). Pemberdayaan masyarakat melalui pengembangan desa wisata dan implikasinya terhadap ketahanan sosial budaya wilayah (studi di desa wisata Penglipuran Bali). Jurnal Ketahanan Nasional, 23(1), 116.

Fadzilah, V. Q. N. (2014). Hubungan perilaku masyarakat tentang kebersihan lingkungan dengan keberadaan tikus di desa lencoh kecamatan selo kabupaten boyolali (Doctoral dissertation, Universitas Muhammadiyah Surakarta).

Khairunnisa, K., Jiwandono, I. S., Nurhasanah, N., Dewi, N. K., Saputra, H. H., \& Wati, T. L. (2019). Kampanye Kebersihan Lingkungan Melalui Program Kerja Bakti Membangun Desa di Lombok utara. Jurnal Pendidikan dan Pengabdian Masyarakat, 2(2).

Raharjana, D. T. (2012). Membangun pariwisata bersama rakyat: Kajian partisipasi lokal dalam membangun Desa wisata di dieng plateau. Jurnal Kawistara, 2(3).

Sulistiyorini, N. R., Darwis, R. S., \& Gutama, A. S. (2015). Partisipasi masyarakat dalam pengelolaan sampah di lingkungan Margaluyu Kelurahan Cicurug. SHARE: Social Work Journal, 5(1).

Widyasari, W. (2017). Faktor Determinan Partisipasi Masyarakat Dalam Gerakan Citarum Bestari Terhadap Perilaku Masyarakat Bersih Lingkungan (Study Deskriptif Di Desa Sangkanhurip Kecamatan Katapang Kabupaten Bandung). Jurnal Pendidikan Luar Sekolah, 13(2).

Wulandari, A. D. (2017). Perilaku peduli lingkungan masyarakat dalam pengelolaan Desa Wisata Kandri Kecamatan Gunungpati Kota Semarang (Doctoral dissertation, Universitas Negeri Semarang). 